\title{
(6) OPEN ACCESS \\ Injury risk is low among world-class volleyball players: 4-year data from the FIVB Injury Surveillance System
}

\author{
Tone Bere, ${ }^{1,2}$ Jacek Kruczynski, ${ }^{3,4}$ Nadège Veintimilla, ${ }^{3}$ Yuichiro Hamu, ${ }^{3}$ \\ Roald Bahr ${ }^{1,2,3}$
}

- Additional material is published online only. To view please visit the journal online (http://dx.doi.org/10.1136/ bjsports-2015-094959).

${ }^{1}$ Aspetar Orthopaedic and Sports Medicine Hospital, Doha, Qatar

${ }^{2}$ Department of Sports Medicine, Oslo Sports Trauma Research Center, Norwegian School of Sport Sciences, Oslo, Norway ${ }^{3}$ Fédération Internationale de Volleyball, Lausanne, Switzerland

${ }^{4}$ Department of General Orthopaedics, Poznan University of Medical Sciences, Oncology and Traumatology, Poznan, Poland

Correspondence to Professor Roald Bahr, Department of Sports Medicine, Oslo Sports Trauma Research Center, Norwegian School of Sport Sciences, PB 4014 Ullevål Stadion, Oslo 0806, Norway; roald@nih.no

Accepted 24 June 2015 Published Online First 20 July 2015

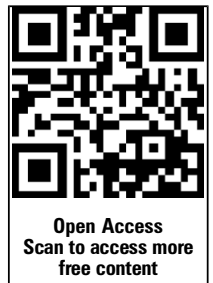

CrossMark

To cite: Bere $\mathrm{T}$,

Kruczynski J, Veintimilla N,

et al. Br J Sports Med

2015:49:1132-1137.

\section{ABSTRACT}

Background Little is known about the rate and pattern of injuries in international volleyball competition. Objective To describe the risk and pattern of injuries among world-class players based on data from the The International Volleyball Federation (FIVB) Injury Surveillance System (ISS) (junior and senior, male and female).

Methods The FIVB ISS is based on prospective registration of injuries by team medical staff during all major FIVB tournaments (World Championships, World Cup, World Grand Prix, World League, Olympic Games). This paper is based on 4-year data (September 2010 to November 2014) obtained through the FIVB ISS during 32 major FIVB events (23 senior and 9 junior).

Results The incidence of time-loss injuries during match play was 3.8/1000 player hours (95\% CI 3.0 to 4.5); this was greater for senior players than for junior players (relative risk: $2.04,1.29$ to 3.21 ), while there was no difference between males and females (1.04, 0.70 to 1.55 ). Across all age and sex groups, the ankle was the most commonly injured body part (25.9\%), followed by the knee (15.2\%), fingers/thumb (10.7\%) and lower back (8.9\%). Injury incidence was greater for centre players and lower for liberos than for other player functions; injury patterns also differed between player functions.

Conclusions Volleyball is a very safe sport, even at the highest levels of play. Preventive measures should focus on acute ankle and finger sprains, and overuse injuries in the knee, lower back and shoulder.

\section{INTRODUCTION}

Volleyball is assumed to be a safe sport compared to other team sports, such as football, handball and basketball, where frequent tackles and opponent contact is a part of the game. ${ }^{1-3}$ However, volleyball players may be at risk for injuries due to sport-specific tasks, such as jumping and landing, as well as spiking and blocking the ball. Two prospective one-season cohort studies from national divisions in Norway and the Netherlands have reported an incidence of three to four injuries per 1000 player hours during competition and one to two injuries per 1000 training hours. ${ }^{4} 5$ Similar estimates owner obtained from 16-year data on women's volleyball from the National Collegiate Athletic Association injury surveillance programme. ${ }^{6}$

At the national level, injuries occur in a certain pattern. ${ }^{4} 5^{7-12}$ Although volleyball is seen as a non-contact game, where the two teams are separated by the net, the most frequent acute injury, an ankle sprain, is often the result of player contact, that is, when a blocker lands on the foot of an opposing attacker, or a teammate, close to the net. ${ }^{13}{ }^{14}$ Volleyball players are also prone to acute finger sprains, which mainly occur in contact with the ball. ${ }^{15} 16$ Similar to other throwing athletes, shoulder problems may result from repetitive spiking and serving, ${ }^{17}$ and a high volume of jump training may cause knee problems. ${ }^{18-22}$ In addition, repetitive stress to the lower back may occur when hitting and during high-velocity jump serving. ${ }^{23}$

The International Volleyball Federation (FIVB) is committed to protecting the health of its athletes: ${ }^{24}$ women and men, as well as senior and junior players, and to prevent them from injuries. However, except for a perfunctory description based on the IOC surveillance programmes during the Olympic Games in Athens 2004, Beijing 2008 and London 2012, ${ }^{1-3}$ there are no data available from the highest level of play. The FIVB Injury Surveillance System (ISS) was therefore established in 2010, modelled on the IOC protocols. ${ }^{25}{ }^{26}$ The FIVB ISS was designed to provide information about the rate and pattern of injuries in FIVB competitions and also offer directions for injury prevention. The ISS also represents a framework for monitoring long-term changes in the frequency and circumstances of injury.

The aim of the current study was to describe the risk and pattern of injuries among world-class players based on FIVB ISS data from all major FIVB events (junior and senior, male and female).

\section{METHODS}

Design

The FIVB ISS is based on prospective registration of injuries during all major FIVB tournaments (World Championships, World Cup, World Grand Prix, World League, Olympic Games), where the medical staff of the participating teams are requested to report all newly incurred injuries. This paper is based on four-year data (September 2010 to November 2014) obtained through the FIVB ISS. During this period, there were 44 major FIVB events (34 senior and 10 junior), and the ISS protocol was followed in 32 of these $(23$ senior and 9 junior).

\section{Injury registration}

During the compulsory Team Doctor's Meeting, held the day before the start of each event, the medical representatives of each team were informed 
by the FIVB Medical Delegate about the FIVB ISS and instructed on how to record injuries. They were provided a booklet outlining the injury registration protocol, definitions and codes. We requested them to report all newly incurred injuries among their athletes during matches and/or training throughout the event. We used a standardised one-page report form with predetermined categories, definitions and codes (see online supplementary appendix), to be completed regardless of whether any injury had occurred or not. For each injury, the report form included information about whether the injury occurred during training or match play (if so, match set), injury location, type of injury, cause of injury and whether the player returned to the game, as well as the estimated severity reported as the time expected for complete return to play (days/weeks). The report form was submitted to the FIVB Medical Delegate at the end of each match at the competition venue. Translations for all definitions and codes used in the report form were available in nine languages: Arabic, English, French, German, Japanese, Polish, Portuguese, Russian and Spanish.

A newly incurred injury was defined as any musculoskeletal complaint newly incurred during match play and/or training during the event that received medical attention regardless of the consequences with respect to absence from competition or training. Pre-existing, not fully rehabilitated injuries were not recorded, and nor were illnesses.

\section{Exposure data}

To present the injury risk as incidences, an exposure file was created in Excel (V.2010). The duration and result of each set and match was extracted from the official FIVB database online and transferred to the Excel file. We calculated the number of player hours throughout the event (6 players $\times$ match duration $\times$ number of returned report forms). Exposure was calculated for each of the five player positions, based on the most common team formation: two outside hitters, one centre (middle blocker), one setter, one diagonal (opposite) player and one libero. Competitions for the under-18, under-19, under-20, under-21 and under-23 age categories were classified as junior events.

\section{Statistical analyses}

The data were analysed using SPSS (SPSS for Windows, V.21.0, SPSS, Chicago, Illinois). Descriptive data, that is, frequencies and proportions, were presented for subgroups, such as injury type, location, cause, circumstance and severity. The injury incidence was presented as the number of match injuries per 1000 player hours. A Z-test based on the Poisson model, was used to compare injury incidences between subgroups. Injury incidences and relative risks (RR) were presented with 95\% CIs, and a twotailed $\mathrm{p}$ value of $\leq 0.05$ was considered significant.

\section{RESULTS}

\section{Injury incidence}

Throughout the 32 events included, 2640 of 2710 report forms were submitted by team medical staff, corresponding to a total response rate of $97.4 \%$. In total, 440 injuries were reported, 275 during match play (62.5\%) and 165 during training (37.5\%). The incidence of match injuries was 10.7/1000 player hours $(95 \%$ CI 9.5 to 12.0$)$; this was greater for senior players than junior players (RR: $1.32,95 \%$ CI 1.03 to 1.69), while there was no difference between males and females (RR: 1.09, 95\% CI 0.86 to 1.38 ) (table 1).

The incidence of time-loss injuries during match play was 3.8/ 1000 player hours (95\% CI 3.0 to 4.5 ). The difference between senior players and junior players was even greater for time-loss injuries (RR: $2.04,95 \%$ CI 1.29 to 3.21), while there was still no difference between males and females (RR: 1.04, 95\% CI 0.70 to 1.55 ) (table 1). The incidence of injuries during match play was greater for centre players than for other player functions (figure 1).

\section{Injury severity}

Across all age and sex groups, the majority of injuries were minimal to mild (table 2). Severe injuries were rare; 10 of 440 injuries were expected to cause an absence of $>4$ weeks. Of these, eight occurred during match play, corresponding to an incidence of 0.3 severe injuries per 1000 player hours (95\% CI 0.1 to 0.5 ).

\section{Injury pattern}

Across all age and sex groups, the ankle was the most commonly injured body part (25.9\%), followed by the knee (15.2\%), finger/thumb (10.7\%) and lumbar/lower back (8.9\%) (table 3). This distribution was almost similar between match play (ankle: 31.3\%, knee: 15.6\%, fingers/thumb: $10.2 \%$ ) and training (ankle: 17.0\%, knee: 13.2\%, lower back: 11.9\%). The most common injury type was joint sprains $(32.5 \%, \mathrm{n}=143)$, followed by muscle strains $(14.1 \%, \mathrm{n}=62)$ and contusions $(12.7 \%$, $\mathrm{n}=56$ ). Joint sprains affected mainly the ankle $(\mathrm{n}=87)$, finger/ thumb $(n=26)$ and knee $(n=17)$, while most muscle strains were located in the lower back $(n=19)$ and thigh $(n=10)$. In total, an ankle sprain was the most frequent specific diagnosis (19.8\%).

The distribution of the five most common injury locations by player function is shown in figure 2. Liberos had a lower proportion of ankle sprains and a greater proportion of finger/

Table 1 Number of injuries ( $n=275)$ and time-loss injuries $(n=97)$ during match play, match exposure (number of player hours), and injury and time-loss injury incidence (injuries per 1000 player hours with $95 \% \mathrm{Cl}$ ) per sex and age group

\begin{tabular}{|c|c|c|c|c|c|c|c|c|c|}
\hline & \multicolumn{3}{|l|}{ Women } & \multicolumn{3}{|l|}{ Men } & \multicolumn{3}{|l|}{ Total } \\
\hline & Junior & Senior & Total & Junior & Senior & Total & Junior & Senior & Total \\
\hline Exposure & 5767 & 7718 & 13485 & 4854 & 7294 & 12148 & 10621 & 15012 & 25633 \\
\hline Injuries & 45 & 94 & 139 & 51 & 85 & 136 & 96 & 179 & 275 \\
\hline Incidence & $\begin{array}{l}7.8 \\
\text { (5.5 to } 10.1 \text { ) }\end{array}$ & $\begin{array}{l}12.2 \\
\text { (9.7 to } 14.6)\end{array}$ & $\begin{array}{l}10.3 \\
\text { (8.6 to } 12.0)\end{array}$ & $\begin{array}{l}10.5 \\
\text { (7.6 to } 13.4)\end{array}$ & $\begin{array}{l}11.7 \\
\text { (9.2 to } 14.1)\end{array}$ & $\begin{array}{l}11.2 \\
\text { (9.3 to } 13.1)\end{array}$ & $\begin{array}{l}9.0 \\
\text { (7.2 to } 10.8)\end{array}$ & $\begin{array}{l}11.9 \\
\text { (10.2 to } 13.7)\end{array}$ & $\begin{array}{l}10.7 \\
\text { (9.5 to } 12.0)\end{array}$ \\
\hline Time-loss injuries & 15 & 35 & 50 & 10 & 37 & 47 & 25 & 72 & 97 \\
\hline Time-loss injury incidence & $\begin{array}{l}2.6 \\
\text { (1.3 to } 3.9 \text { ) }\end{array}$ & $\begin{array}{l}4.5 \\
\text { (3.0 to } 6.0 \text { ) }\end{array}$ & $\begin{array}{l}3.7 \\
\text { (2.7 to } 4.7 \text { ) }\end{array}$ & $\begin{array}{l}2.1 \\
\text { (0.8 to } 3.3 \text { ) }\end{array}$ & $\begin{array}{l}5.1 \\
\text { (3.4 to } 6.7 \text { ) }\end{array}$ & $\begin{array}{l}3.9 \\
\text { (2.8 to } 5.0 \text { ) }\end{array}$ & $\begin{array}{l}2.4 \\
\text { (1.4 to } 3.3 \text { ) }\end{array}$ & $\begin{array}{l}4.8 \\
\text { (3.7 to } 5.9 \text { ) }\end{array}$ & $\begin{array}{l}3.8 \\
(3.0 \text { to } 4.5)\end{array}$ \\
\hline
\end{tabular}




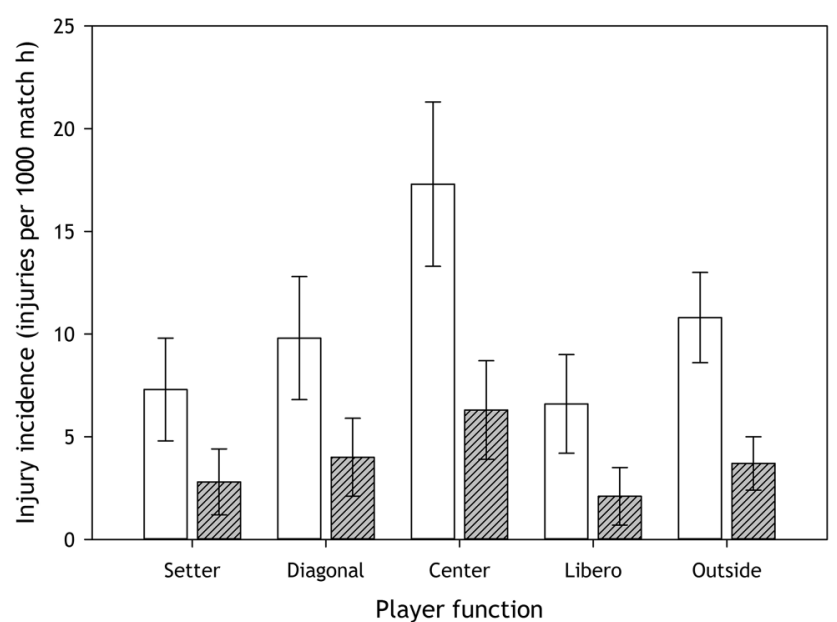

Figure 1 Total injury incidence and time-loss injury incidence (with $95 \% \mathrm{Cl}$ ) during match play for the different player functions $(n=97)$.

thumb injuries than other player functions, while setters had relatively fewer knee injuries and outside hitters more shoulder injuries.

\section{Injury causes}

In total, $23.0 \%$ of all injuries $(n=101)$ were reported as the result of contact between players, while 20.7\% $(n=91)$ were overuse injuries, and $17.3 \%(n=76)$ were reported as noncontact trauma. The distribution of injury causes reported for the three most common injury locations, ankle, knee and finger/ thumb injuries, are shown in table 4 . The most common cause of ankle injuries was contact with another player, while noncontact trauma and overuse were reported as the most common causes of knee injuries. Finger/thumb injuries were mainly caused by contact with a moving object.

\section{Match timing and result}

Injury incidence did not differ between the first (7.7 injuries per $1000 \mathrm{~h}, 95 \%$ CI 5.7 to 9.8$)$, second $(9.8,7.5$ to 12.1$)$, third (9.0, 6.8 to 11.2$)$, fourth $(8.7,5.6$ to 11.8$)$ and fifth set $(9.2$, 2.8 to 15.5$)$. Also, there was no difference in injury incidence between the winning and losing team.

\section{DISCUSSION}

This is the first study to provide detailed information on injuries among world-class volleyball players. Our main finding was that

Table 2 Injury severity ( $n=440$, with percentages), expressed as the expected duration of absence from full participation in training and match play, by age group and sex

\begin{tabular}{lccccc}
\hline Absence & $\begin{array}{l}\text { Senior } \\
\text { men }\end{array}$ & $\begin{array}{l}\text { Senior } \\
\text { women }\end{array}$ & $\begin{array}{l}\text { Junior } \\
\text { men }\end{array}$ & $\begin{array}{l}\text { Junior } \\
\text { women }\end{array}$ & Total \\
\hline No absence & $45(38.8)$ & $63(48.1)$ & $53(51.0)$ & $47(52.8)$ & $208(47.3)$ \\
$1-2$ days & $29(25.0)$ & $19(14.5)$ & $11(10.6)$ & $18(20.2)$ & $77(17.5)$ \\
$3-7$ days & $11(9.5)$ & $13(9.9)$ & $4(3.8)$ & $3(3.4)$ & $31(7.0)$ \\
8-28 days & $10(8.6)$ & $6(4.6)$ & $4(3.8)$ & $5(5.6)$ & $25(5.7)$ \\
$>4$ weeks & $1(0.9)$ & $5(3.8)$ & $1(1.0)$ & $0(0)$ & $7(1.6)$ \\
$\geq 6$ months & $1(0.9)$ & $2(1.5)$ & $0(0)$ & $0(0)$ & $3(0.7)$ \\
Information & $19(16.4)$ & $23(17.6)$ & $31(29.9)$ & $16(18.0)$ & $89(20.2)$ \\
missing & & & & & \\
Total (\%) & $116(100)$ & $131(100)$ & $104(100)$ & $89(100)$ & $440(100)$ \\
\hline
\end{tabular}

Table 3 Body part injured ( $n=440$, with percentages) by age group and sex

\begin{tabular}{|c|c|c|c|c|c|}
\hline Body part injured & $\begin{array}{l}\text { Senior } \\
\text { men }\end{array}$ & $\begin{array}{l}\text { Senior } \\
\text { women }\end{array}$ & $\begin{array}{l}\text { Junior } \\
\text { men }\end{array}$ & $\begin{array}{l}\text { Junior } \\
\text { women }\end{array}$ & Total \\
\hline Face & $2(1.7)$ & $7(5.3)$ & $6(5.8)$ & $5(5.6)$ & $20(4.5)$ \\
\hline Head & $3(2.6)$ & $3(2.3)$ & $1(1.0)$ & $0(0)$ & $7(1.6)$ \\
\hline Neck/cervical spine & $0(0)$ & $2(1.5)$ & $1(1.0)$ & $1(1.1)$ & $4(0.9)$ \\
\hline Thorax/upper back & $1(0.9)$ & $1(0.8)$ & $0(0)$ & $2(2.2)$ & $4(0.9)$ \\
\hline Sternum/ribs & $1(0.9)$ & $1(0.8)$ & $1(1.0)$ & $0(0)$ & $3(0.7)$ \\
\hline Lumbar/lower back & $12(10.3)$ & $16(12.2)$ & $7(6.7)$ & $4(4.5)$ & $39(8.9)$ \\
\hline Abdomen & $3(2.6)$ & $3(2.3)$ & $0(0)$ & $0(0)$ & $6(1.4)$ \\
\hline $\begin{array}{l}\text { Pelvis/sacrum/ } \\
\text { buttock }\end{array}$ & $2(1.7)$ & $2(1.5)$ & $2(1.9)$ & $0(0)$ & $6(1.4)$ \\
\hline Shoulder/clavicle & $4(3.4)$ & $1(0.8)$ & $10(9.6)$ & $7(7.9)$ & $22(5.0)$ \\
\hline Upper arm & $1(0.9)$ & $0(0)$ & $0(0)$ & $1(1.1)$ & $2(0.5)$ \\
\hline Elbow & $2(1.7)$ & $0(0)$ & $0(0)$ & $2(2.2)$ & $4(0.9)$ \\
\hline Forearm & $0(0)$ & $0(0)$ & $1(1.0)$ & $0(0)$ & $1(0.2)$ \\
\hline Wrist & $1(0.9)$ & $2(1.5)$ & $0(0)$ & $2(2.2)$ & $5(1.1)$ \\
\hline Hand & $3(2.6)$ & $2(1.5)$ & $4(3.8)$ & $2(2.2)$ & $11(2.5)$ \\
\hline Finger/thumb & $9(7.8)$ & $12(9.1)$ & $15(14.4)$ & $11(12.3)$ & $47(10.7)$ \\
\hline Hip & $0(0)$ & $4(3.1)$ & $3(2.9)$ & $1(1.1)$ & $8(1.8)$ \\
\hline Groin & $3(2.6)$ & $0(0)$ & $1(1.0)$ & $0(0)$ & $4(0.9)$ \\
\hline Thigh & $4(3.4)$ & $8(6.1)$ & $1(1.0)$ & $6(6.7)$ & $19(4.3)$ \\
\hline Knee & $19(16.4)$ & $24(18.3)$ & $14(13.5)$ & $10(11.2)$ & $67(15.2)$ \\
\hline Lower leg & $4(3.4)$ & $2(1.5)$ & $10(9.6)$ & $4(4.5)$ & $20(4.5)$ \\
\hline Achilles tendon & $3(2.6)$ & $3(2.3)$ & $1(1.0)$ & $1(1.1)$ & $8(1.8)$ \\
\hline Ankle & $34(29.3)$ & $35(26.7)$ & $18(17.3)$ & $27(30.3)$ & $114(25.9)$ \\
\hline Foot/toe & $4(3.4)$ & $3(2.3)$ & $8(7.7)$ & $2(2.2)$ & $17(3.9)$ \\
\hline Information missing & $1(0.9)$ & $0(0)$ & $0(0)$ & $1(1.1)$ & $2(0.5)$ \\
\hline Total $(\%)$ & $116(100)$ & $131(100)$ & $104(100)$ & $89(100)$ & $440(100)$ \\
\hline
\end{tabular}

the injury risk was low, with no gender difference, but with somewhat higher rates among senior players than junior players. We also observed differences in the risk and pattern of injuries between different player functions.

\section{Injury risk}

Total injury incidence during match play was 10.7 per 1000 player hours, which is substantially lower than that reported in other team sports at the elite level. ${ }^{1-3}$ In total, $32.5 \%$ of all injuries were reported to cause subsequent time-loss, which corresponds to an incidence of 3.8 time-loss injuries per 1000 player hours. This injury rate is consistent with previous prospective studies reporting time-loss injuries from lower levels of play: national club volleyball, ${ }^{45}$ collegiate volleyball, ${ }^{6}$ world-class professional beach volleyball ${ }^{27}$ and the USA national club championship. ${ }^{12}$ Direct comparison of these rates with older epidemiological volleyball injury studies should be done with caution due to differences in study methodology, such as, injury definition, study design, player population and exposure calculation. ${ }^{8-11}$ However, in accordance with the majority of previous studies, we found that across all age and sex groups, most injuries were minimal to mild with subsequent time loss from training and/or match play of 0-2 days. This study also shows that severe injuries are rare; only 10 reported injuries were expected to cause an absence of $>4$ weeks. Of these, eight occurred during match play, corresponding to an incidence of only 0.3 severe injuries per 1000 player hours, which is substantially lower than other major team sports like football, ${ }^{28}{ }^{29}$ handball $^{3}{ }^{30}$ or ice hockey. ${ }^{3132}$

We found no differences in the risk of injury between males and females. However, senior players had a greater injury 
Figure 2 Body part injured versus player function for the five most common injury locations $(n=426)$.

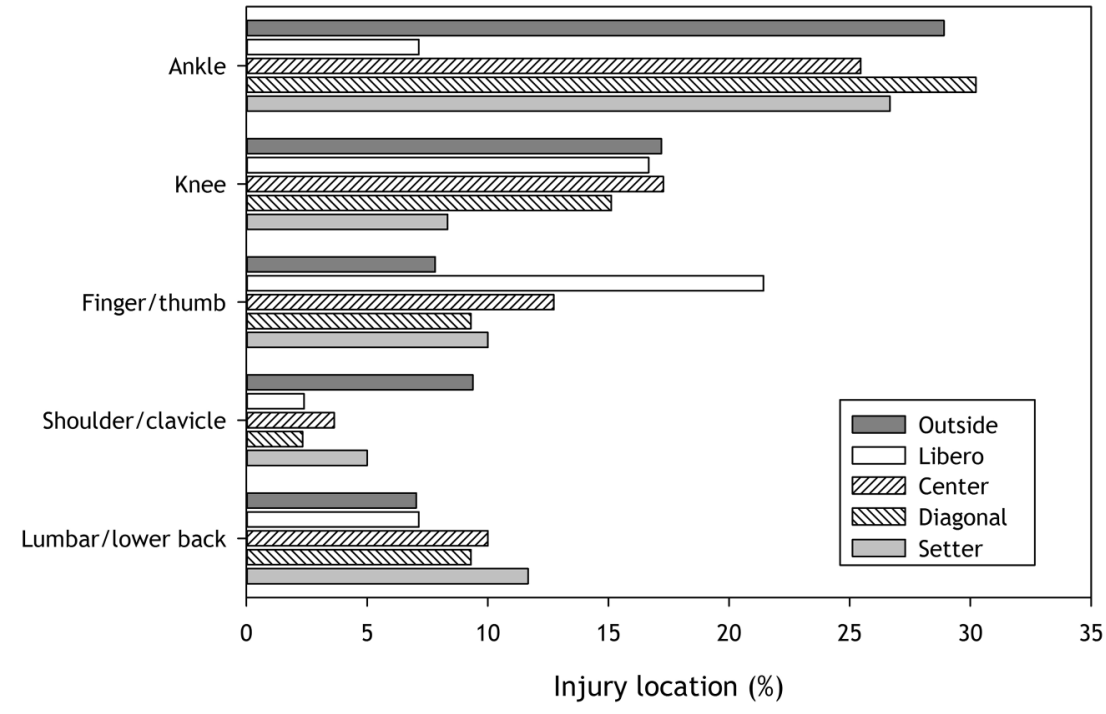

incidence than junior players. It seems reasonable to assume that this may be related to match intensity, that is, faster play, greater ball velocity, higher jumps and larger forces acting on the player. ${ }^{33}$ Also, the competition calendar for the best senior players is saturated, with a year-round programme of alternating club and national team competitions. Senior players may be at particular risk for overuse injuries, as there is little time for preparation and recovery. ${ }^{7} 91518$ On the other hand, senior players would be expected to make fewer technical mistakes and use better judgement in high-risk situations.

\section{Injury pattern}

The pattern of injury observed in this study is consistent with findings from previous studies from the national club level 1020 years ago, reporting that the most common acute injuries in volleyball are located in the ankle and fingers (including the thumb), while overuse problems mainly affect the knee, lower back and shoulder. ${ }^{4} 5$ 7-12

However, while we found that ankle injuries accounted for $25.9 \%$ of all injuries, previous studies have reported a proportion of about $50 \% .^{4}$ This may reflect that technical mistakes and foot conflicts when landing from blocking duels are less common among highly skilled players. However, it should be noted that the rate of ankle sprains among female US collegiate players decreased by $1.8 \%$ per year from 1988 to $2004 .^{6}$

Table 4 Distribution of injury causes reported for the three most common injury locations. Data are shown as the number of cases (\%)

\begin{tabular}{lccc}
\hline Injury cause & $\begin{array}{l}\text { Ankle } \\
\text { injuries } \\
(\mathbf{n}=114)\end{array}$ & $\begin{array}{l}\text { Knee } \\
\text { injuries } \\
(\mathbf{n}=67)\end{array}$ & $\begin{array}{l}\text { Finger/thumb } \\
\text { injuries } \\
(\mathbf{n}=47)\end{array}$ \\
\hline Overuse (gradual onset) & $5(4.4)$ & $14(20.9)$ & $0(0)$ \\
Contact with another player & $54(47.4)$ & $13(19.4)$ & $7(14.9)$ \\
Contact: moving object & $4(3.5)$ & $1(1.5)$ & $36(76.6)$ \\
Contact: stagnant object & $3(2.6)$ & $6(9.0)$ & $1(2.1)$ \\
Overuse (sudden onset) & $2(1.8)$ & $5(7.5)$ & $0(0)$ \\
Field of play condition & $4(3.5)$ & $1(1.5)$ & $0(0)$ \\
Non-contact trauma & $29(25.4)$ & $16(23.9)$ & $1(2.1)$ \\
Recurrence of previous injury & $6(5.3)$ & $8(11.9)$ & $1(2.1)$ \\
Other & $2(1.8)$ & $2(3.0)$ & $0(0)$ \\
Information missing & $5(4.4)$ & $1(1.5)$ & $1(2.1)$ \\
\hline
\end{tabular}

Although ankle sprain is still the most common injury type in volleyball, these findings indicate that the risk may have decreased. Effective injury prevention programmes are available, ${ }^{45}$ based on balance training, technical training (emphasising proper spike approach, take-off and landing technique, in addition to block movement drills), balance board training and external ankle supports, ${ }^{16}$ but we do not know to what extent these are being used.

We observed that knee injuries accounted for $15.2 \%$ of all injuries, which is higher than previously reported in studies using a time-loss injury definition, ${ }^{4-6} 10$ but similar or slightly lower than studies using a medical-attention definition. ${ }^{9} 11 \quad 12$ This apparent discrepancy may be explained by the high prevalence of patellar tendinopathy, ${ }^{19} 2022$ a condition which rarely leads to time loss, in spite of substantial pain and reduced performance. Differences in injury definitions used may also explain why we observed a higher proportion of finger/thumb injuries $(10.7 \%)$ compared to previous studies. ${ }^{4-68}$ Again, although these injuries are painful, players often continue playing after securing the injured finger with tape; these injuries will therefore be underreported when using a time-loss injury definition.

\section{How do injuries happen?}

Most injuries in volleyball are related to sport-specific tasks, such as repetitive jumping and landing, as well as spiking and blocking the ball. $.^{5} 7-12$ We found that $23.0 \%$ of all injuries were reported as contact injuries, while $20.7 \%$ were overuse injuries, and $17.3 \%$ were reported as non-contact trauma. We expect that the true magnitude of overuse injuries is even greater than captured in this study, as players often continue to compete despite having chronic overuse injuries. ${ }^{34}$

Almost half (47.4\%) of the ankle injuries occurred in contact with another player, which is consistent with the literature reporting that the most common injury situation is when a blocker lands on the foot of an opposing attacker, or a teammate, close to the net. ${ }^{13}{ }^{14}$ We also observed that overuse (28.4\%) was the most commonly reported cause of knee injuries, which most likely is related to the high prevalence of patellar tendinopathy, associated with a high volume of jump training. ${ }^{16} 19 \quad 20 \quad 35$ Finger injuries were mainly caused by contact with the ball, which is in accordance with the literature reporting that a typical situation is during a block where the ball hits the fingertips and causes a high impact to the extended and 


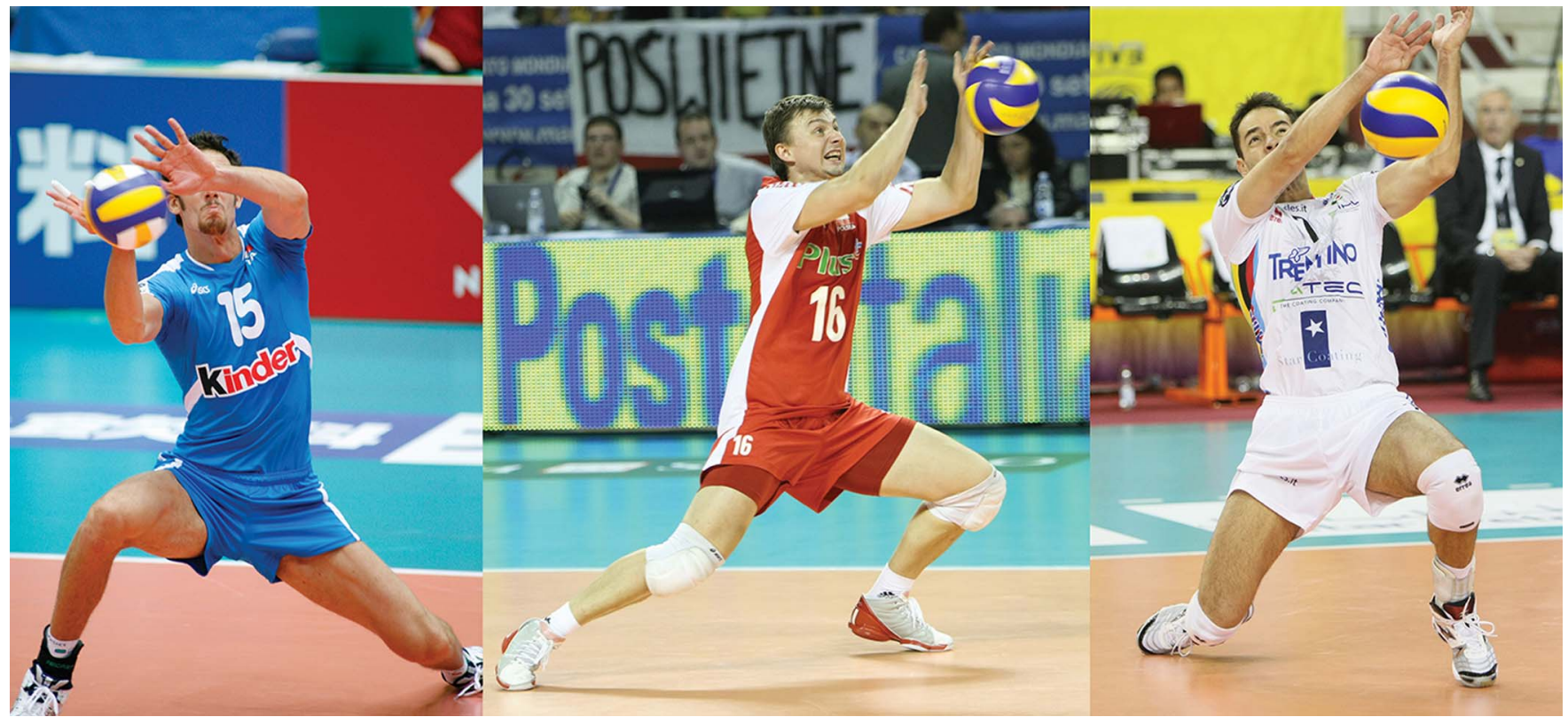

Figure 3 Overhand defensive techniques are frequently used in the back court, leading to a risk of finger injuries, particularly among libero players. Photo courtesy of The International Volleyball Federation (FIVB).

spread fingers. ${ }^{15} 16$ However, it should be noted that rule changes have led to the development of new effective defensive techniques, the overhand dig, a common and effective defensive action used to stop hard-driven spikes in the back court (figure 3). This has been described as an additional mechanism for finger injuries in beach volleyball. ${ }^{27}$

However, describing the exact injury mechanisms can be difficult, as they usually happen quickly and often involve several players. Questionnaire data may therefore be inaccurate. To obtain more precise information on the exact mechanisms of acute volleyball injuries, systematic analyses of videos of real injury situations is a better approach. ${ }^{36} 37^{\circ}$

\section{Does player position matter?}

Previous studies agree that most injuries occur close to the net, related to the three front players on each team: attackers and the opposing team's blockers. ${ }^{4-10}{ }^{12}$ This study extends our understanding by providing the first position-specific injury rates, correcting for exposure, documenting that centre players had a higher injury incidence than other player functions. Centre players are positioned in the middle of the front row, and are substituted for specialised defensive players, liberos, in the back row after serving. This means that centre players have nearly all their exposure in the front row, they jump and land frequently when blocking and spiking, and thus have a greater risk of contact with teammates or opponents.

Liberos, in contrast, had the lowest injury risk and a lower proportion of ankle sprains than other player functions, a finding supported by previous studies among club players. ${ }^{4} 7$ This observation is not surprising, as all their exposure is in the back row, where they are normally not involved in the net duels typically leading to ankle sprains. Also, even if they are not involved in blocking actions by the net, they had a greater proportion of finger and thumb injuries, which may be explained by a high frequency of overhand defensive actions in the back row, as discussed above.

Outside hitters displayed a relatively large proportion of shoulder injuries. This is logical, as they are the main attackers.
The extremely mobile shoulder joint allows hitters to swing high for a spike, which over time may cause shoulder overuse problems. $^{17}$

\section{Practical implications}

Preventive efforts in volleyball should focus on acute ankle and finger/thumb injuries, as well as overuse problems affecting the knee, lower back and shoulder. Several intervention strategies exist to reduce the risk of ankle sprain, including practising proper footwork at the net, proprioceptive exercises integrated in regular conditioning programmes, modification of the centre line, and consistent use of external ankle braces. ${ }^{16}$ Supervised injury prevention programmes can reduce the risk of acute ankle sprain significantly. ${ }^{8} 13 \quad 38$ To prevent knee overuse injuries, several factors should be considered, for example, activity modification, volume of jump training, degree of knee flexing and 'toeing in' while landing, and the composition of the playing surface. ${ }^{18-20}$ Tailored strengthening and conditioning exercises for the thigh, hip and core muscles to effectively absorb impacts during landing from repetitive jumps may also be useful. To prevent finger/thumb injuries, proper technique when spiking and blocking is essential, ${ }^{15} 16$ but technique training for overhead defensive actions in the back row may also be important. How to prevent overuse injuries? There is less evidence available for prevention of overuse problems to the lower back and shoulder, but it is suggested that preventive measures should focus on load reduction (limiting the number of spikes and jump serves) and correction of technique, as well as any underlying imbalances of strength and flexibility through an appropriate training programme, including scapular stabilisation and core strengthening. ${ }^{17} 23$

\section{Methodological considerations}

This study had a response rate of $97.4 \%$, which indicates high compliance by the team medical staff. At least at the senior level, teams had professional medical staff who knew their players very well and could be expected to provide reliable data. Still, like any surveillance programme, the results presented must be considered as minimum estimates of injury incidence. ${ }^{39}$ 
We found that overuse problems accounted for $20.7 \%$ of all injuries. Most likely, this represents a gross underestimate of the true magnitude of overuse problems in this elite player population. A study of world-class beach volleyball players documented that while a 'traditional' cohort study approach using a time-loss injury definition suggested that injury risk was very low, a concurrent survey of pain problems in the shoulder, knees and lower back demonstrated that overuse injuries were highly prevalent. ${ }^{34}$ The same can be expected of this study. ${ }^{40}$ To obtain a more valid picture of overuse problems among players, the Oslo Sports Trauma Research Centre (OSTRC) Overuse Injury Questionnaire has been developed, ${ }^{41}$ but this approach is not easy to implement in an international event setting.

\section{SUMMARY}

The injury risk among world-class volleyball players is low. Senior players are at a higher risk of injury than juniors, while there is no difference between males and females. The risk and pattern of injuries vary according to player function. Preventive measures should focus on acute ankle and finger sprains, and overuse injuries in the knee, lower back and shoulder.

\section{What are the new findings?}

- The injury risk among world-class volleyball players is low.

- Senior players are at higher risk than junior players, while there is no difference between males and females.

- The risk and pattern of injuries vary according to the player function.

\section{How might it impact on clinical practice in the near future?}

Preventive measures should focus on acute ankle and finger sprains, and overuse injuries in the knee, lower back and shoulder.

Acknowledgements The authors would like to thank the senior management of the FIVB for their support of the FIVB ISS. The authors are grateful to the FIVB Medical Delegates, Dr Bruno Borges da Fonseca, Dr Andres Pina del Rosario, Dr Hossam Bahgat, Prof Manfred Holzgraefe, Dr Bernard Nau, Dr Annie Peytavin, Dr Fernando Avila España, Professor Mamadou Ndoye and Dr Ufuk Demirkilic, for their outstanding cooperation and contribution to the FIVB ISS. The authors would also like to thank all team medical staff who have dutifully completed all the injury forms.

Contributors All authors contributed to the study design and data recoding preparation. RB, NV, YH and JK were responsible for data collection. TB and RB analysed and interpreted the data and wrote the first draft of the paper. All authors contributed to the final paper. TB, NV and RB are responsible for the overall content as guarantors.

Funding The FIVB ISS has been established based on financial support from the FIVB. The Oslo Sports Trauma Research Center has been established at the Norwegian School of Sport Sciences through generous grants from the Royal Norwegian Ministry of Culture, the South-Eastern Norway Regional Health Authority, the International Olympic Committee, the Norwegian Olympic Committee \& Confederation of Sport, and Norsk Tipping AS.

Competing interests None declared.

Ethics approval The study has been approved by the Regional Ethics Committee Midt-Norge.

Provenance and peer review Not commissioned; externally peer reviewed.
Open Access This is an Open Access article distributed in accordance with the Creative Commons Attribution Non Commercial (CC BY-NC 4.0) license, which permits others to distribute, remix, adapt, build upon this work non-commercially, and license their derivative works on different terms, provided the original work is properly cited and the use is non-commercial. See: http://creativecommons.org/ licenses/by-nc/4.0/

\section{REFERENCES}

1 Engebretsen L, Soligard T, Steffen $\mathrm{K}$, et al. Sports injuries and illnesses during the London Summer Olympic Games 2012. Br J Sports Med 2013;47:407-14.

2 Junge A, Engebretsen L, Mountjoy ML, et al. Sports injuries during the Summer Olympic Games 2008. Am J Sports Med 2009;37:2165-72.

3 Junge A, Langevoort G, Pipe A, et al. Injuries in team sport tournaments during the 2004 Olympic Games. Am J Sports Med 2006:34:565-76.

4 Verhagen EA, Van der Beek AJ, Bouter LM, et al. A one-season prospective cohort study of volleyball injuries. Br J Sports Med 2004a;38:477-81.

5 Bahr B, Bahr IA. Incidence of acute volleyball injuries: a prospective cohort study of injury mechanisms and risk factors. Scand J Med Sci Sports 1997;7:166-71.

6 Agel J, Palmieri-Smith RM, Dick R, et al. Descriptive Epidemiology of Collegiate Women's Volleyball Injuries: National Collegiate Athletic Association Injury Surveillance System, 1988-1989 Through 2003-2004. J Athl Train 2007:42:295-302.

7 Beneka A, Malliou P, Gioftsidou A, et al. Injury incidence rate, severity and diagnosis in male volleyball players. Sport Sci Health 2009;5:93-9.

8 Augustsson J, Thomeé R, Svantesson U. Injuries and preventive actions in elite Swedish volleyball. Scand J Med Sci Sports 2006;16:433-40.

9 Aagaard H, Jørgensen U. Injuries in elite volleyball. Scand J Med Sci Sports 1996;6:228-32.

10 Solgård L, Nielsen AB, Møller-Madsen B, et al. Volleyball injuries presenting in casualty: a prospective study. Br J Sports Med 1995;29:200-4.

11 Watkins J, Green BN. Volleyball injuries: a survey of injuries of Scottish National League male players. Br J Sports Med 1992;26:135-7.

12 Schafle MD, Requa RK, Patton WL, et al. Injuries in the 1987 national amateur volleyball tournament. Am J Sports Med 1990;18:624-31.

13 Verhagen E, van $\operatorname{der}$ Beek A, Twisk J, et al. The effect of a proprioceptive balance board training program for the prevention of ankle sprains: a prospective controlled trial. Am J Sports Med 2004b;32:1385-93.

14 Bahr R, Karlsen R, Lian $\varnothing$, et al. Incidence and mechanisms of acute ankle inversion injuries in volleyball. A retrospective cohort study. Am J Sports Med 1994:22:595-600

15 Eerkes K. Volleyball injuries. Curr Sports Med Rep 2012;11:251-6.

16 Reeser JC, Verhagen E, Briner WW, et al. Strategies for the prevention of volleyball related injuries. Br J Sports Med 2006;40:594-600.

17 Seminati $E$, Minetti AE. Overuse in volleyball training/practice: a review on shoulder and spine-related injuries. Eur J Sports Sci 2013:13:732-43.

18 Bahr MA Bahr R. Jump frequency may contribute to risk of jumper's knee: a study of interindividual and sex differences in a total of 11943 jumps video recorded during training and matches in young elite volleyball players. Br J Sports Med 2014:48:1322-6.

19 Visnes H, Bahr R. Training volume and body composition as risk factors for developing jumper's knee among young elite volleyball players. Scand J Med SCi Sports 2013;23:607-13.

20 Visnes $H$, Aandahl $H \AA$, Bahr R. Jumper's knee paradox--jumping ability is a risk factor for developing jumper's knee: a 5-year prospective study. $\mathrm{Br}$ I Sports Med 2013:47:503-7.

21 Zwerver J, Bredweg SW, van den Akker-Scheek I. Prevalence of jumper's knee among nonelite athletes from different sports: a cross-sectional survey. Am J Sports Med 2011:39:1984-8

22 Lian $\varnothing$, Engebretsen L, Bahr R. Prevalence of jumper's knee among elite athletes from different sports: a cross-sectional study. Am J Sports Med 2005;33:561-7

23 Smith C, Nyland J, Caudill P, et al. Dynamic trunk stabilization: a conceptual back injury prevention program for volleyball athletes. J Orthop Sports Phys Ther 2008:38:703-20

24 Engebretsen L, Bahr R, Cook JL, et al. The IOC Centres of Excellence bring prevention to sports medicine. Br J Sports Med 2014;48:1270-5.

25 Engebretsen L, Steffen K, Alonso JM, et al. Sports injuries and illnesses during the Winter Olympic Games 2010. Br J Sports Med 2010;44:772-80.

26 Junge $A$, Engebretsen $L$, Alonso JM, et al. Injury surveillance in multi-sport events: the International Olympic Committee approach. Br J Sports Med 2008:42:413-21.

27 Bahr R, Reeser JC. Injuries among world-class professional beach volleyball players. Am J Sports Med 2003;31:119-25.

28 Ekstrand J, Hagglund M, Kristenson K, et al. Fewer ligament injuries but no preventive effect on muscle injuries and severe injuries: an 11-year follow-up of the UEFA Champions League injury study. Br J Sports Med 2013:47:732-7.

29 Dvorak J, Junge A, Derman W, et al. Injuries and illnesses of football players during the 2010 FIFA World Cup. Br J Sports Med 2011;45:626-30. 
30 Langevoort G, Myklebust G, Dvorak J, et al. Handball injuries during major international tournaments. Scand J Med Sci Sports 2007;17:400-7.

31 Markku T, Stuart MJ, Aubry M, et al. Injuries in men's international ice hockey: a 7 -year study of the International Ice Hockey Federation Adult World Championship Tournaments and Olympic Winter Games. Br J Sports Med 2015;49:30-6.

32 Soligard T, Steffen K, Palmer-Green D, et al. Sports injuries and illnesses in the Sochi 2014 Olympic Winter Games. Br J Sports Med 2015;49:441-7.

33 Sheppard JM, Nolan E, Newton RU. Changes in strength and power qualities over two years in volleyball players transitioning from junior to senior national team. J Strength Cond Res 2012;26:152-7.

34 Bahr R. No injuries, but plenty of pain? On the methodology for recording overuse symptoms in sports. Br I Sports Med 2009:43:966-72.

35 Lian Ø, Refsnes PE, Engebretsen L, et al. Performance characteristics of volleyball players with patellar tendinopathy. Am J Sports Med 2003;31:408-13.

36 Krosshaug $\mathrm{T}$, Andersen $\mathrm{TE}$, Olsen $\mathrm{OE}$, et al. Research approaches to describe the mechanisms of injuries in sport: limitations and possibilities. Br I Sports Med 2005;39:330-9.
37 Bere T, Bahr R. Injury prevention advances in alpine ski racing: harnessing collaboration with the International Ski Federation (FIS), long-term surveillance and digital technology to benefit athletes. Br I Sports Med 2014;48:738.

38 Bahr R, Lian O, Bahr IA. A twofold reduction in the incidence of acute ankle sprains in volleyball after the introduction of an injury prevention program: a prospective cohort study. Scand J Med Sports 1997;7:172-7.

39 Bjørnebo J, Flørenes TW, Bahr R, et al. Injury Surveillance in male professional football; is medical staff reporting complete and accurate? Scand J Med Sci Sports 2011;21:713-20

40 Clarsen B, Bahr R, Heymans MW, et al. The prevalence and impact of overuse injuries in five Norwegian sports: application of a new surveillance method. Scand I Med Sci Sports 2015;25:323-30.

41 Clarsen B, Myklebust G, Bahr R. Development and validation of a new method for the registration of overuse injuries in sports injury epidemiology: the Oslo Sports Trauma Research Centre (OSTRC) Overuse Injury Questionnaire. Br I Sports Med 2013;47:495-502. 